\title{
Editorial
}

\section{Road safety: the potholes of neglect}

H.A. Geziary, ${ }^{1}$ H. El Sayed, ${ }^{2}$ S.J. Hussain ${ }^{3}$ and H.I. Sakr ${ }^{3}$

Stepping up its response to the global road safety crisis, the World Health Organization (WHO) dedicated the theme of World Health Day 2004, celebrated on 7 April, to road traffic injury prevention. This year's slogan, "Road Safety Is No Accident", stresses that road traffic injuries do not happen by mere chance. Most such injuries are both predictable and preventable. Conventional thinking around the concept of "accidents" has changed drastically, as road traffic injuries have become one of the most important public health issues of the new century. World Health Day 2004 was an important opportunity to highlight this issue, and the facts that contribute to the problem in order to strengthen collective efforts to curb the growing epidemic of road traffic injuries.

As every day bids us goodbye, as many as 3000 people will have been killed and 100000 more injured on the world's roads [1]. The toll is heavy and the impact often lasts longer than we imagine, very often forever. To pay due respect and bring recognition to the millions who are killed and injured as a result of road crashes annually, the "World Day of Remembrance for Road Accident Victims" is observed across the world on the third Sunday of November every year. This year, it is of even greater significance as the long neglected issue of road safety has received more attention than usual.

The World Health Day campaign also witnessed the launch of the joint WHO/ World Bank World report on road traffic injury prevention, which focuses on the specific role of public health and described the magnitude of road traffic injuries, risk factors for such injuries and ways to prevent them [1].

Driving new efforts to reduce the global burden of road traffic injuries are resolutions of the United Nations General Assembly and the World Health Assembly. In April 2004, the United Nations General Assembly adopted resolution 58/289 on "Improving Global Road Safety" [1] in which it invited WHO to act, in collaboration with the United Nations regional commissions, as a coordinator on road safety issues within the United Nations system. In May 2004 the World Health Assembly accepted the invitation in resolution WHA57/10 on "Road Safety and Health" [2].

Some may wonder why WHO and the health sector should take the lead in an issue such as road safety, which has traditionally been the domain of the transport or police sectors. The fact is, however, that road traffic crashes pose a major public health problem that has long been neglected. It is health workers who must witness

${ }^{1}$ Regional Director, World Health Organization, Regional Office for the Eastern Mediterranean, Cairo, Egypt.

${ }^{2}$ Clinical Epidemiology Unit, Faculty of Medicine, Suez Canal University, Ismailia, Egypt (email: heshamel2002@yahoo.com).

${ }^{3}$ Injury and Violence Prevention Unit, World Health Organization, Regional Office for the Eastern Mediterranean, Cairo, Egypt. 
their awful, and largely avoidable, consequences [2]. Moreover, the health sector, by virtue of its effectiveness in producing science-based evidence, can contribute significantly to the identification of effective interventions to reduce this burden.

Globally, road traffic crashes claim the lives of some 1.2 million people every year, and about 20 million to 50 million people are injured or disabled [1]. They account for $2.6 \%$ of all disability-adjusted life years lost and $2.1 \%$ of global mortality. Almost $50 \%$ of this global mortality is borne by people between the ages of 15 and 44 yearsamong the most productive years of life [1].

Low-income and middle-income countries account for about $90 \%$ of global mortality due to road traffic crashes. Since the 1980 s, these countries have shown an increase in deaths due to road traffic injuries, in contrast to an overall decrease in highincome countries [1]. If current trends persist, by 2020 the annual deaths and disabilities due to road traffic injuries will have dropped by $30 \%$ in high-income countries. Globally, however, they will have risen by $60 \%$, signifying an immense increase in the annual toll of deaths and disabilities from road traffic injuries in low-income and middle-income countries [3].

Besides the devastating human losses, economic losses due to road traffic injuries are enormous. Estimates suggest that their cost accounts for $1 \%$ to $2 \%$ of the gross national product of different countries, amounting to approximately US\$520 billion globally [4]. Of this, US\$ 65 billion is borne by developing countries - more than the amount such countries receive in development aid in a year.

Over the past decade, the number of road traffic deaths has been rising steadily in the WHO Eastern Mediterranean Region
$[5,6]$. In 2002 , the mortality rate from road traffic injuries in the Region was 26.4 deaths per 100000 population, the second highest in the world after the African Region [7].

There are many reasons for the high number of casualties in the Eastern Mediterranean Region. The high burden of road traffic injuries among vulnerable road users-including pedestrians, children, and bicycle/motorcycle and public transport users - is characteristic of most countries of the Region. Pedestrians account for almost half the deaths due to road traffic crashes in the Region [8]. Furthermore, emergency services and medical facilities are often inadequate, and vehicle conditions and protective devices are generally below internationally accepted standards. Overcrowding of vehicles and poor infrastructure, such as substandard roads and lack of safe pedestrian facilities, are other contributing factors [9]. Overcrowding at times tends to manifest in many dangerous forms; in most low-income countries of the Region it is common to see people (particularly schoolchildren) sitting atop an overcrowded public vehicle.

There are other economic and social dimensions to the issue of road safety. It is also an issue of equity. Studies have shown that individuals from disadvantaged socioeconomic groups or living in poorer areas are at greatest risk of being killed or injured as a result of a road traffic crash. To make matters worse, poorer populations often cannot afford health care at the more sophisticated private health facilities. Moreover, when the breadwinner of a family becomes disabled or dies, the family is pushed deeper into poverty [10].

In recent years there has been growing realization of the escalating problem of road traffic injuries among countries of the East-

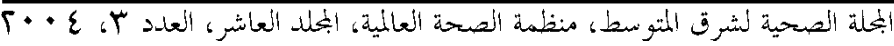


ern Mediterranean Region. A number of efforts and interventions are being undertaken by the countries to tackle the issue at different levels [2]. However, many challenges are yet to be addressed. One of the major challenges related to road traffic injuries in the Region is the poor quality of data. Even if data at some level exist, often there may be significant discrepancies between the figures issued by the various sectors involved in the recording and reporting of road traffic crashes and injuries. There is an urgent need to assess the actual situation in different countries realistically and thoroughly. Data collection and research on various risk factors of road traffic injuries is one of the major responsibilities of the health sector in this respect [2].

Establishing evidence-based knowledge and creating awareness about the magnitude of the problem should serve as the first step to enable countries to develop effective and sustainable strategies and interventions for the prevention of road traffic crashes and their sequelae. These should be tailored to fit regional conditions and variations among countries of the Region with respect to cultural and socioeconomic considerations. Such strategies must also be complemented by systematic follow up of the implementation and evaluation of adopted interventions.

Improving road safety will entail strong political commitment and priority at all levels of government in collaboration with other public and private stakeholders. A multisectoral approach is essential, with one lead agency identified for coordinating efforts of the different sectors involved. The contribution of key sectors, such as health, transport, education, police and finance, together with other stakeholders is vital. The lead agency should be given all necessary resources and made publicly accountable.

While working for the creation of a safety-conscious culture and environment, road safety should encompass the protection of vulnerable road users. Comprehensive and sustainable solutions should involve equitably setting up a less hostile traffic environment for everyone, particularly those most at risk.

Legislation continues to be crucial, but laws can only work when the public is convinced that they will be enforced. The attitude of law enforcement personnel in this respect is pivotal. They should follow and abide by all traffic regulations themselves at all times [2]. Efforts to create a "traffic atmosphere" that is congenial to all segments of society should not be limited to a one-time activity, but should be part of a sustained and systematic process.

Strengthening pre-hospital and trauma care for road traffic victims is another crucial task. Many lives can be saved if appropriate and competent post-crash treatment is provided in well coordinated and well equipped establishments.

In conclusion, World Health Day should not be merely an event to celebrate but a commitment towards a cause, dedication to an objective and a promise for a better future. The problem of road safety and road traffic injuries must be tackled and the time to act is now. Together, we must push for commitment and further action at global, regional and country levels to stop the death toll on our roads and contain a growing epidemic that is largely avoidable. 


\section{References}

1. Peden $\mathrm{M}$ et al., eds. World report on road traffic injury prevention2. Geneva, World Health Organization, 2004.

2. World Health Day 2004: Road safety is no accident. A resource document for the WHO Eastern Mediterranean Region. Cairo, World Health Organization, Regional Office for the Eastern Mediterranean, 2004.

3. World Health Day 2004: Road Safety is No Accident. Geneva, World Health Organization, 2004.

4. Jacobs G, Aeron-Thomas A, Astrop A. Estimating global road fatalities. Crowthorne, UK, Transport Research Laboratory, 2000 (TRL Report, No. 445).

5. Bener A et al. Strategy to improved road safety in developing countries. Saudi medical journal, 2003, 24:447-52.

6. Ghaffar A, Hyder AA, Masud TI. The burden of road traffic injuries in the developing world: the first national injury survey of Pakistan. Public health, 2004, 18:2117.
7. WHO Global Burden of Disease Project (GBD). Estimates by WHO Region. Available at: http://www3.who.int/whosis menu.cfm?path=evidence, burden,burden estimates,burden_estimates_2002N, burden_estimates_2002N_2002Rev, burden_estimates_2002N_2002Rev Region\& language=english (accessed 9 December 2004).

8. Downing AJ, IA Sayer, Zaheer-ul-Islam M. Pedestrian safety in the developing world. Asian Road Safety Conference, Kuala Lumpur, Malaysia, 25-28 October 1993. Crowthorne, UK, Transport Research Laboratory, 1993.

9. Hamam AM, El-Sayed HF. Injury in Egypt: "the hidden epidemic". Trauma quarterly, 1999, 14(3):261-7.

10. Nantulya VM, Reich MR. Equity dimensions of road traffic injuries in low- and middle-income countries. Injury control and safety promotion, 2003, 10(1/2):1320.

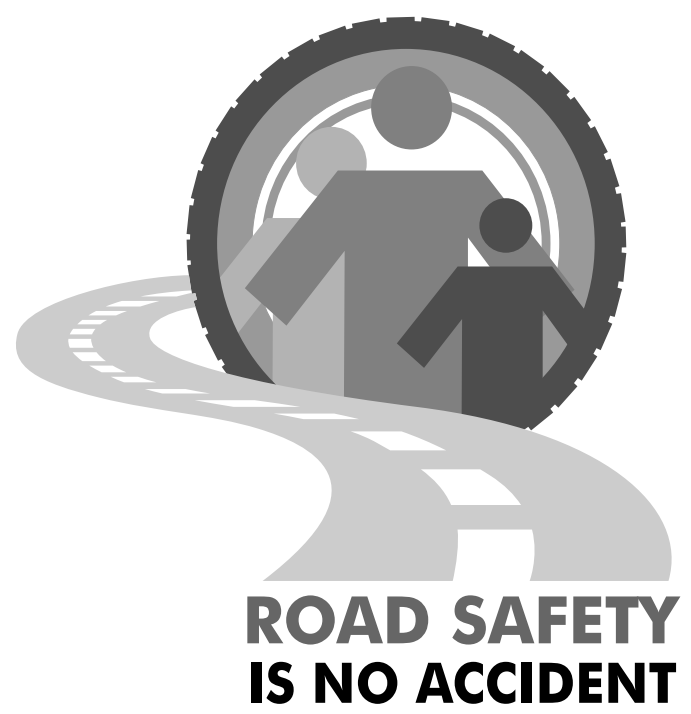

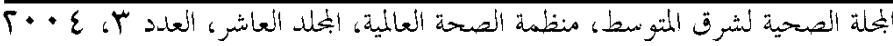

